\title{
Launching a Global Network of Virologists: The World Society for Virology (WSV)
}

\author{
Ahmed S. Abdel-Moneim ${ }^{a, b}$ Anupam Varmac Flor H. Pujol $^{d}$ George K. Lewis $^{e}$ \\ Janusz T. Paweska ${ }^{f} \quad$ Jesús L. Romalde ${ }^{g}$ Maria Söderlund-Venermo ${ }^{h}$ \\ Matthew D. Moore ${ }^{i}$ Michael M. Nevels, ${ }^{j, k}$ Vikram N. Vakharial Vinod Joshi ${ }^{m}$ \\ Yashpal Singh Malik ${ }^{\mathrm{n}}$ Zhengli Shi $^{\mathrm{O}}$ Ziad A. Memish ${ }^{\mathrm{p}, \mathrm{q}}$ \\ ${ }^{a}$ Microbiology Department, College of Medicine, Taif University, Taif, Saudi Arabia; ${ }^{b}$ Virology Department, Faculty of \\ Veterinary Medicine, Beni-Suef University, Beni-Suef, Egypt; ${ }^{\mathrm{C}}$ Advanced Centre for Plant Virology, Indian Agricultural \\ Research Institute, New Delhi, India; ${ }^{d}$ Laboratorio de Virología Molecular, Instituto Venezolano de Investigaciones \\ Cientificas (IVIC), Caracas, Venezuela; ${ }^{e}$ Division of Vaccine Research, Institute of Human Virology, Maryland University, \\ Baltimore, MD, USA; ${ }^{\mathrm{f} C e n t r e ~ f o r ~ E m e r g i n g ~ Z o o n o t i c ~ a n d ~ P a r a s i t i c ~ D i s e a s e s, ~ N a t i o n a l ~ I n s t i t u t e ~ f o r ~ C o m m u n i c a b l e ~}$ \\ Diseases, Sandringham, South Africa; ${ }^{9}$ Departamento de Microbiología y Parasitología, CIBUS-Facultad de Biología, \\ Universidade de Santiago de Compostela, Santiago de Compostela, Spain; ${ }^{\text {h}}$ Department of Virology, Helsinki \\ University, Helsinki, Finland; 'Department of Food Science, University of Massachusetts, Amherst, MA, USA; ${ }^{j}$ Biomedical

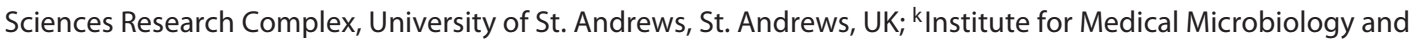 \\ Hygiene, University of Regensburg, Regensburg, Germany; 'Institute of Marine and Environmental Technology, \\ University of Maryland, Baltimore, MD, USA; ${ }^{m}$ Amity Institute of Virology and Immunology, Amity University, \\ Sector-125, Uttar Pradesh, India; ${ }^{\mathrm{n}}$ Indian Veterinary Research Institute, Bareilly, India; ${ }^{\circ}$ Center for Emerging Infectious \\ Diseases, Wuhan Institute of Virology, Chinese Academy of Sciences, Wuhan, China; ${ }^{\mathrm{P} C o l l e g e}$ of Medicine, Alfaisal \\ University, Riyadh, Saudi Arabia; ${ }^{9}$ Research Department and Division of Infectious Diseases, Department of Medicine, \\ Prince Mohamed Bin Abdulaziz Hospital, Ministry of Health, Riyadh, Saudi Arabia
}

Dear Editor,

We are introducing the World Society for Virology (WSV). WSV is a global coalition of virologists that strongly supports the One Health approach. The WSV's stated purpose is to help virologists by developing and improving collaboration, education, and guidance. WSV is committed to serving virologists worldwide by (1) connecting virologists working both in public and private sectors to enhance virology research and development, especially in lowand middle-income countries that often lack the required resources; (2) educating, communicating, and enhancing the exchange of data on new developments and

Ahmed S. Abdel-Moneim is the founder of the World Society for Virology. progress in virology research; (3) enhancing discovery and exchange of human, animal, plant, food, and environmental samples around the globe for virus studies; and (4) promoting high-quality virology research.

The concept of WSV was born out of ResearchGate, a social network that also connects scientists and scholars worldwide with little restriction. It should be emphatically stated that the intention of WSV is not to replace or duplicate the efforts of existing societies or professional networks. The premise of WSV is that the technology now exists to allow the establishment and maintenance of an international virology society without limitation of border, ethnicity, or resource. This idea has already attracted an increasing number of virologists and scientists in related fields to join WSV, with membership numbers steadily increasing over the course of 6 months, including people from over 60 countries in Africa, Asia, Australia, Europe, Latin America, and North America.

WSV is incorporated as a non-profit organization in the USA and is currently pursuing 501(c)(3) status. The only requirement to join the society is an interest in virology, public health, and/or viral diseases and their management. There are currently four types of WSV memberships, all free of charge: (i) honorary membership; (ii) full membership; (iii) corporate membership; and (iv) early-stage membership (including students). All members have the right to vote in the elections of the president, vice president, secretary, treasurer, and execu-

\section{KARGER}

(C) 2018 S. Karger AG, Basel

E-Mail karger@karger.com

www.karger.com/int
Ahmed S. Abdel-Moneim

Virology Department, Faculty of Veterinary Medicine

Beni-Suef University, Mokbel Street

Beni-Suef 62511 (Egypt)

E-Mail info@ws-virology.org or asa@bsu.edu.eg 
tive board members, and receive equal access to all WSV resources. Three main functionary committees exist to lead WSV: the Managing Committee, the Training and Career-Development Committee, and the Membership Review Committee (www. ws-virology.org). WSV continues to accept new members to its different committees with the goal of having most of the world's countries or regions represented.

In order to encourage the collaboration of colleagues all over the world, WSV has sought and seeks partnerships with differ- ent virology and microbiology societies. WSV is currently partnered with the Indian Virological Society, Mexican Virology Networking, Colombian Association of Virology, Finnish Society for Study of Infectious Diseases, Societas Biochemical, Biophysica et Microbiologica Fenniae, Moroccan Society of Virology, and Chinese Society for Virology - Division of the Chinese Society for Microbiology.

Overall, WSV is a global society for virologists. The explicit focus of WSV is promoting and enhancing virological science and education, with the broader goal of promoting the welfare of humanity through reduced barriers to collaboration and information. The growing membership and interest of official partners from well-established national and international virology societies/organizations is a good indicator of the leap taken by the society. All virologists, from students to institution leaders, are invited to join this global network, and all virology societies are invited to become partners of WSV (www. ws-virology.org). 